\title{
Identification of particulate matter and vitreous fibres in the atmosphere of a megacity
}

\author{
P. Avino, C. Fanizza \& M. Manigrasso \\ Dipartimento Insediamenti Produttivi ed Interazione con l'Ambiente- \\ ISPESL, Rome, Italy
}

\begin{abstract}
This paper reports the preliminary results of our investigation. The levels of organic carbon, elemental carbon and PTS with their relative relationships and evidence of presence of man-made vitreous fibres are reported and discussed. These preliminary results underline the importance and the necessity of a systematic approach in such studies.

Keywords: particulate matter, man-made vitreous fibres, elemental carbon, urban pollution.
\end{abstract}

\section{Introduction}

The characterization of atmospheric particulate matter and man-made vitreous fibres represents a very important aspect for the air quality evaluation and for their relative effects on the population both in industrial areas and in a megacity.

The particulate, also called "aerosol" or "dust", is constituted by all the suspended non-gaseous material present in atmosphere. From the dimensional point of view the definition of the various kind of particulate contemplates four categories, according to the dimension of the particle aerodynamic diameter $\left(\mathrm{d}_{\mathrm{a}}\right)$ : ultrafine $\left(\mathrm{d}_{\mathrm{a}} \leq 0.1 \mu \mathrm{m}\right)$; fine $\left(0.1 \mu \mathrm{m} \leq \mathrm{d}_{\mathrm{a}} \leq 2.5 \mu \mathrm{m}\right)$; coarse $\left(2.5 \mu \mathrm{m} \leq \mathrm{d}_{\mathrm{a}} \leq 10 \mu \mathrm{m}\right)$; total particulate matter $(>10 \mu \mathrm{m})$. The particulate matter with aerodynamic diameter up to $50 \mu \mathrm{m}$ is commonly called as particulate suspended matter (PTS). The chemical particle composition (carbonaceous fraction, organic fraction, metals, etc.) results important for the sanitary-toxicological aspect. In particular carbonaceous aerosols have been the focus of the attention in recent years because of their properties and their ubiquitous presence in atmosphere. Usually, carbonaceous aerosol constituents are classified into elemental carbon (EC), or 
black carbon, and organic carbon (OC), fractions differing for their chemicalphysical properties $[1,2]$. The OC represent the amount of the carbonaceous particulate matter that can be oxidised at $350^{\circ} \mathrm{C}$ (oxidation of $\mathrm{HC}$ to $\mathrm{CO}_{2}$ ) and has both primary and secondary origin.

Primary particulate $\mathrm{OC}$ is formed during combustion and associated mainly as submicron particles. In fact, mechanical processes involved in the emission of plant spores and pollen and vegetation debris, produce coarse primary organic aerosol particles [3]. Particulate OC has also a secondary origin from gas-toparticle conversion of volatile organic compounds in atmosphere, either as effect of the condensation of low vapour pressure volatile organics or resulting from physical or chemical adsorption of gaseous on aerosol particle surfaces $[4,5]$.

EC has a primary origin, in fact it is basically an anthropogenic pollutant emitted as a result of incomplete combustion of fossil and carbonaceous fuels. EC constitutes the fraction of carbonaceous aerosols that can be oxidized at a temperature of $750^{\circ} \mathrm{C}$. The sum of OC and EC represents the total carbon (TC), i.e. the total carbonaceous fraction present in the atmospheric particulate.

A fibre is defined as a particle with an aspect ratio, i.e. a ratio of the length to the width of a particle, greater than 3:1. Fibres which are $5 \mu \mathrm{m}$ or longer and have a diameter of less than $3.0 \mu \mathrm{m}$ are considered breathable, due to their dimensions they are capable of being inhaled and deposited deep into the lungs. The International Agency for Research on Cancer (IARC) classified in 1987 asbestos as carcinogenic for humans, group 1 [6].

Owing to its thermal and mechanical properties, together with its wear resistance, asbestos had been widely used in several merceological sectors, till it was banned by the law n. 257 in 1992 [7]. After this year, in industrial and civil applications the man-made vitreous fibres (MMVFs) have been used.

From a toxicological point of view, in 1998 IARC classified the asbestos' substitutes as possibly carcinogenic to humans (group 2B) because their potential human carcinogenic effects whereas in 2002 it confirmed the ceramic fibres in the group 2B and the other fibres (e.g., glass wool fibre) were not classifiable as to theirs carcinogenicity to humans (group 3) showing no human carcinogenic effects.

In this contest, considering the sanitary importance to be exposed to the particulate matter and airborne fibres, a study focused to the simultaneous determination of these two pollutants in the urban area of Rome. In this paper are reported the results of an intensive measurement campaign performed in a frame of a project focused to the investigation of the particulate matter composition in megacity.

\section{Experimental}

\subsection{Sampling sites}

Aerosol and fibres samples were collected in the Pilot Station located at the ISPESL's building in downtown Rome, near S.M. Maggiore Cathedral, (Figure 1): the area is characterized by anthropogenic sources 


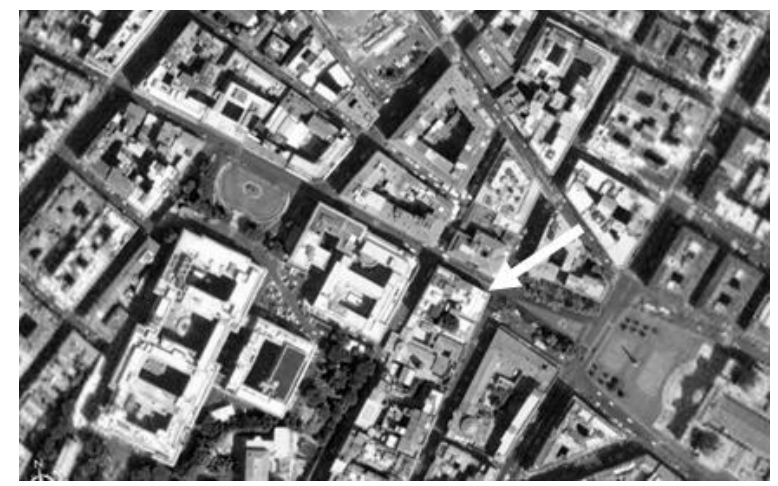

Figure 1: $\quad$ Sampling site in downtown Rome.

\subsection{Measurement method}

The separation of EC and OC was carried out by means an Ambient Carbon Particulate Monitor 5400 (Rupprecht \& Patashnik Co Inc., Albany, NY, USA) based on a two step combustion procedure. During the first step, i.e. precombustion step, the samples were heated up to the first operating temperature $\left(350^{\circ} \mathrm{C}\right)$. When the first desorption was completed, the sample was further burned at $750^{\circ} \mathrm{C}$ in order to perform EC measurement. By means a nondispersive infrared detector (NDIR) the instrument measures $\mathrm{CO}_{2}$ amounts released both two steps.

The total mass particulate matter was monitored by a TEOM Ambient Particulate Monitor (R\&P). Both the two instruments were equipped with a PM10 sampling head.

\subsection{Fibres analysis by Scanning Electron Microscopy}

The fibre sampling and analysis are performed according the ISO/FDIS 14966 International Standard regulation where both the characteristics and the chemical composition of the asbestos and synthetic inorganic fibres are described [8]. The sampling for the fibre analysis was performed in two different periods: for 13 days in November 2002 and for few days in December 2002. For each day 16 samples of 90-minutes long are collected. All the sampling was performed by a sequential sampler (CF 20) using metal filter and polycarbonate filtering membrane with $25 \mathrm{~mm}$ diameter and $0.8 \mu \mathrm{m}$ porosity.

All of the samples were analyzed by a Scanning Electron Microscopy (SEM) (LEO 440 S) couplet with an X-ray Energy Dispersion Spectrometer (EDS) (INCA Energy 400).

These samples were divided in two groups, one related to the diurnal period (from 7.00 to 20.30) and one to the night period (from 20.30 to 7.00) for evaluating the differences between the activities performed during the studied periods. 


\section{Results and discussion}

In researches involving the characterization the choice of the sampling site is very important: the place is strongly influenced by anthropogenic emission sources (autovehicular traffic, domestic heating, etc.) and, no in direct way, by natural emission fluxes (biogenic sources). Further, the ISPESL building is located in a narrow street delimited by tall blocks and the wind circulation is typical of a tunnel situation.

In Table 1 are reported the concentration levels of OC, EC and PM10 $\left(\mu \mathrm{g} / \mathrm{m}^{3}\right)$ determined at the ISPESL Pilot Station during the campaign. As shown, EC ranges between 5.2 and $14.9 \mu \mathrm{g} / \mathrm{m}^{3}$ whereas OC between 4.8 and $10.2 \mu \mathrm{g} / \mathrm{m}^{3}$. From a qualitative point of view the EC/OC ratio is always above 1 except November $9^{\text {th }}$ and $11^{\text {th }}$ : this $i$ san index of an higher contribution of the anthropogenic emission on the carbonaceous fraction instead of those due to the physical-chemical transformations producing secondary organic carbon.

Table 1: $\quad$ Levels $\left(\mu \mathrm{g} / \mathrm{m}^{3}\right)$ and ratios $(\%)$ in Rome.

\begin{tabular}{|l|rrccccc|}
\hline & OC & EC & TC & PM10 & EC/OC & EC/PM & TC/PM \\
\hline $09 / 11 / 03$ & 5.7 & 5.2 & 10.9 & 22.5 & 0.91 & 23.0 & 48.4 \\
$10 / 11 / 03$ & 6.9 & 6.9 & 13.8 & 39.1 & 1.00 & 17.6 & 35.3 \\
$11 / 11 / 03$ & 6.3 & 6.1 & 12.4 & 35.4 & 0.97 & 17.1 & 34.9 \\
$12 / 11 / 03$ & 10.2 & 14.9 & 25.1 & 54.1 & 1.46 & 27.6 & 46.4 \\
$13 / 11 / 03$ & 6.3 & 6.4 & 12.7 & 45.8 & 1.02 & 14.0 & 27.8 \\
$14 / 11 / 03$ & 7.2 & 8.0 & 15.2 & 85.4 & 1.11 & 9.3 & 17.8 \\
$15 / 11 / 03$ & 6.9 & 7.8 & 14.7 & 49.4 & 1.13 & 15.8 & 29.8 \\
$16 / 11 / 03$ & 7.0 & 8.8 & 15.7 & 40.6 & 1.26 & 21.6 & 38.7 \\
$17 / 11 / 03$ & 6.3 & 7.2 & 13.5 & 65.5 & 1.14 & 11.0 & 20.5 \\
$18 / 11 / 03$ & 7.0 & 8.2 & 15.2 & 59.2 & 1.17 & 13.9 & 25.7 \\
$19 / 11 / 03$ & 6.4 & 6.5 & 12.9 & 50.4 & 1.02 & 12.9 & 25.6 \\
$16 / 12 / 03$ & 6.0 & 7.4 & 13.4 & 45.1 & 1.23 & 16.4 & 29.7 \\
$17 / 12 / 03$ & 4.8 & 5.4 & 10.2 & 30.9 & 1.13 & 17.5 & 33.0 \\
\hline
\end{tabular}

In Table 1 the last column reporting the ratio between total carbon and PM10 is very interesting: in fact, in downtown Rome TC represents a fraction ranging from $18 \%$ to $48 \%$ of the PM10. Furthermore, from the same table the EC/PM10 ratio can be still derived $(9 \div 27 \%)$ : this shows that the contribution to the anthropogenic fraction in urban areas is averagely $20 \%$ of the total particulate matter composition. Combining these two latter considerations we can affirm that an autovehicular traffic reduction affects only the EC carbonaceous fraction whereas it does not influence the total mass because a lot of different species contribute to it.

In Figure 2 the PM10, OC and EC trends are reported from December $14^{\text {th }}$ to $17^{\text {th }}$. As it can be seen there is good agreement among the curves: in particular, the correlation factor $(\mathrm{R})$ between $\mathrm{OC}$ and $\mathrm{EC}$ is 0.883 and the two species have 
their behaviours almost overlapping. Further, the temporal trends of EC and PM10 are very similar ( $\mathrm{R}$ is 0.901 ) even if the PM10 levels are obviously higher than the EC values for presence of other species such as sulphate, nitrate, metals, etc. Basically, the daily PM10 and TC variations are related to the emission fluxes from the autovehicular traffic but are strictly connected with radon level modulation considered as tracer of the dynamic of the boundary layer evolution [9]. Finally, during the diurnal hours of the $16^{\text {th }}$ it should be noted that a PM10 peak $\left(120 \mu \mathrm{g} / \mathrm{m}^{3}\right)$ was observed as well the highest fibre concentration.

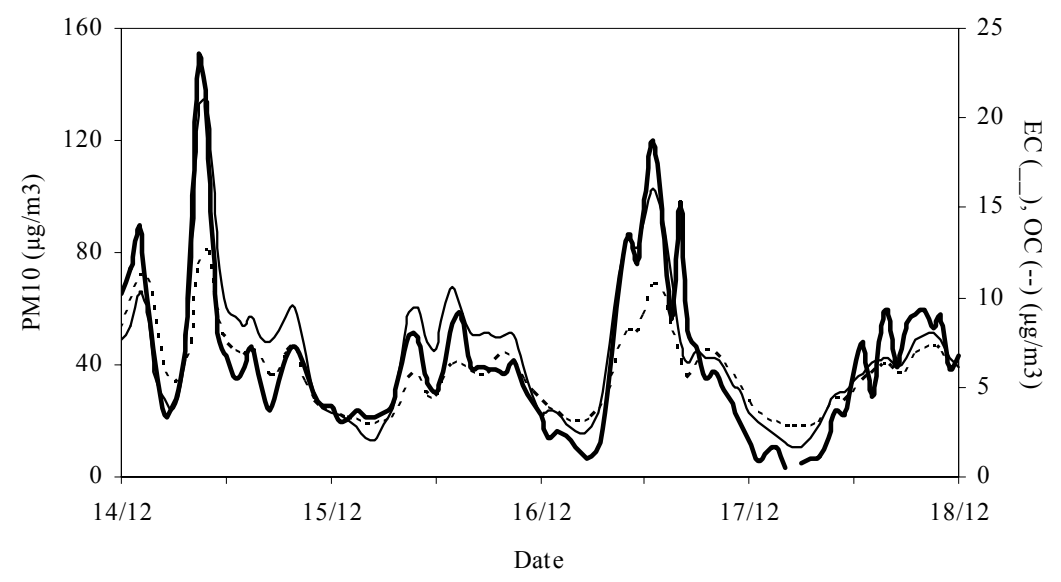

Figure 2: $\quad \mathrm{PM}, \mathrm{EC}$ and $\mathrm{OC}$ in downtown Rome.

Table 2: $\quad$ MMVFs concentration and number in Rome.

\begin{tabular}{|c|cc|cc|}
\hline Date & \multicolumn{2}{|c|}{ Concentration (F/l) } & \multicolumn{2}{c|}{ Vitreous fibre (n) } \\
& day & night & day & night \\
\hline $09 / 11$ & 0.12 & 0.053 & 0 & 0 \\
$10 / 11$ & 0.25 & 0.10 & 0 & 0 \\
$11 / 11$ & 0.08 & 1 & 0 & 1 \\
$12 / 11$ & 0.16 & 0,1 & 2 & 0 \\
$13 / 11$ & 0.08 & 0.1 & 0 & 0 \\
$14 / 11$ & 0.12 & 0.053 & 0 & 0 \\
$15 / 11$ & 0.12 & 0.10 & 1 & 0 \\
$16 / 11$ & 0.041 & 0 & 0 & 0 \\
$17 / 11$ & 0.12 & 0 & 1 & 0 \\
$18 / 11$ & 0.2 & 0.1 & 0 & 0 \\
$19 / 11$ & 0.12 & 0.053 & 0 & 0 \\
$16 / 12$ & 0.12 & 0.053 & 0 & 0 \\
$17 / 12$ & 0 & 0 & 0 & 0 \\
\hline
\end{tabular}




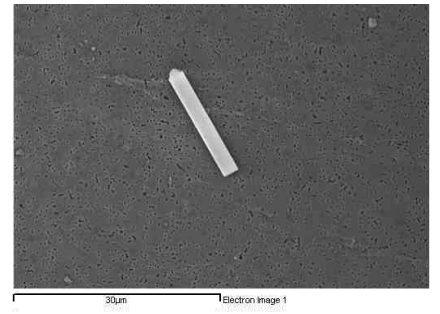

Figure 3: $\quad$ Glass wool fibre.

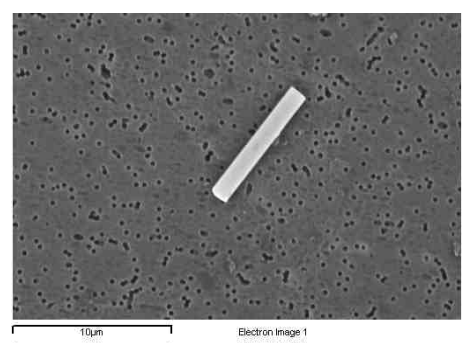

Figure 4: $\quad$ Rock wool fibre.
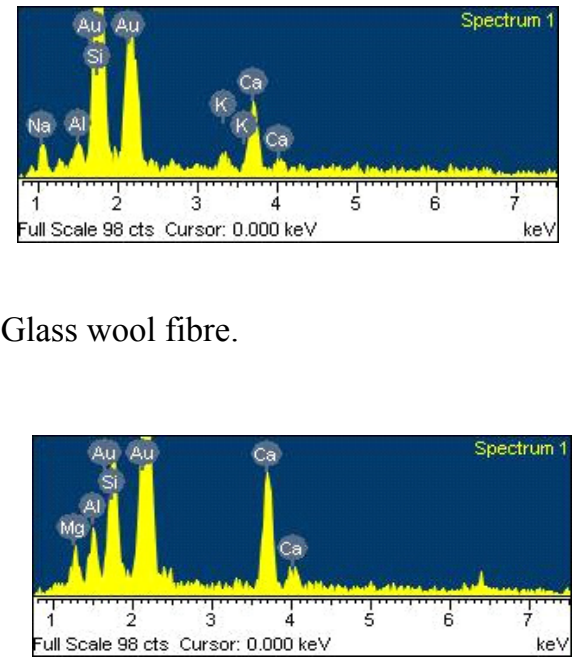

In Table 2 are reported the fibre concentrations (F/l) and the vitreous fibre number during the same day and night periods considered above. The first consideration is no asbestos fibres to be present in any analyzed samples. During the fall campaign some MMVFs are evidenced with different composition, e.g. glass wool fibres (Figure 3) and rock wool fibre (Figure 4). Furthermore, some inorganic fibres are found with chemical composition quite similar to the MMVFs (calcium silicate, iron and chromium) but with dissimilar morphology: in any case, the $\mathrm{Ca}_{2} \mathrm{SO}_{4}$ fibre number is very low and consequently there is no influence on the results.

It should be underlined that in the analyzed fibres a high fibre concentration is found in some periods: we can assume a stability atmospheric condition favouring the pollutant persistence in air.

The results obtained are related only at a single seasonal campaign performed during a fall period which is characterized by frequent raining influencing the particulate matter level and the dust sedimentation. For these reasons other campaigns will be conducted during a dry and hot period and simultaneously in areas not directly influenced by anthropogenic sources such as in side a green park.

\section{References}

[1] Avino, P., Brocco, D., Lepore, L., Ventrone, I. Fundamental aspects of carbonaceous particulate measurements in the study of air pollution in urban area. Air Pollution 2000, ed. C. Brebbia, WIT Press: Wessex, UK, pp. 301-309, 2000. 
[2] Avino, P., Brocco, D., Lepore, L., Ventrone, I. Distribution of elemental carbon (EC) and organic carbon (OC) in the atmospheric aerosol particles of Rome. Journal of Aerosol Science, 31, pp. S364-S365, 2000.

[3] Turpin, B.J., Huntzicker, J.J. Identification of secondary organic aerosol episodes and quantitation of primary and secondary organic aerosol concentrations during SQAQS. Atmospheric Environment, 29, pp. 35273544, 1995.

[4] Rogge, W.F., Mazurek, M.A., Hildemann, L.M., Cass, G.R., Simoneit, B.R.T. Quantification of urban organic aerosols at a molecular level: identification, abundance and seasonal variation. Atmospheric Environment, 27A, pp. 1309-1330, 1993.

[5] Kuhlbusch, T.A.J., Hertlein, A.M., Schütz, L.W. Sources, determination, monitoring and transport or carbonaceous aerosols in Mainz, Germany. Atmospheric Environment, 32, pp. 1097-1110, 1998.

[6] International Agency for Research on Cancer (IARC), Monograph, Asbestos, vol. 14, suppl. 7, 1987.

[7] Law 27 March 1992 n. 257. Norme relative alla cessazione dell'impiego dell'amianto. Serie Ordinaria Gazzetta Ufficiale n. 087, Serie Generale Parte Prima, Suppl. 064 del 13-04-1992.

[8] ISO 14966/2002. Ambient air - Determination of numerical concentration of inorganic fibrous particles - Scanning electron microscopy method.

[9] Avino, P., Brocco, D., Lepore, L., Pareti, S. Interpretation of atmospheric pollution phenomena in relationship with the vertical atmospheric remixing by means of natural radioactivity measurements (Radon) of particulate matter. Annali di Chimica, 93, pp. 589-594, 2003. 